\title{
Sérgio Rezende. Zuzu Angel. Chico Buarque de Hollanda. Lamarca. Charles Dickens. Saberes interligados na narrativa cinematográfica
}

\author{
Maria Ignês Carlos Magno \\ Doutora em Ciências da Comunicação pela ECA/USP. \\ Professora da Universidade Anhembi Morumbi e \\ da Fundação Escola de Sociologia e Política de São Paulo. \\ E-mail: unsigster@gmail.com
}

\section{Angélica}

Quem é essa mulher

Que canta sempre esse estribilho?

Só queria embalar meu filho

Que mora na escuridão do mar.

Quem é essa mulher

Que canta sempre esse lamento?

Só queria lembrar o tormento

Que fez meu filho suspirar.

Quem é essa mulher

Que canta sempre o mesmo arranjo?

Só queria agasalhar meu anjo.

Quem é essa mulher

Que canta como dobra um sino?

Queria cantar por meu menino

Que ele não pode mais cantar.

Miltinho/Chico Buarque 
Era o melhor de todos os tempos

Era o pior dos tempos

Era ainda a idade da sabedoria

Era a idade do disparate

Era a época da fé

Era a época da descrença

Era a estação da Lua

Era a estação da treva

Era a primavera da esperança

Era o inverno do desespero

Tínhamos tudo à nossa frente

Não tínhamos nada à nossa frente

Em suma

Era uma época tão semelhante à atual,

que algumas das mais espalhafatosas autoridades

insistiam em ser aceitas,

para o bem ou para o mal,

apenas no grau superlativo.

Deuses ou demônios.

Charles Dickens

Não é desconhecido que o cinema pode ser abordado sob diferentes ângulos: como objeto teórico, trabalho para especialistas que se consagram à análise da imagem; como experiência estética no sentido kantiano de "objeto de uma satisfação desinteressada" ou como uma experiência de vida, sustenta Arnaud Guigue ${ }^{1}$. Não é novidade também que pode ser fonte de ensino e matéria-prima para apreendermos acontecimentos históricos e culturais. No entanto, e a despeito de sabermos tudo isso, o cinema ainda não faz parte do conjunto de disciplinas que compõem os currículos escolares. Uma das dificuldades talvez esteja no fato de o professor, por não ter conhecimento específico da matéria cinema, correr o risco de tomá-lo apenas como ilustração dos acontecimentos, sem uma análise crítica dos fatos apresentados ou da forma como eles são oferecidos pelo cineasta.

Entendendo que a palavra crítica significa pôr em questionamento, e considerando que tanto os currículos como os acontecimentos organizados nos manuais escolares, na mídia impressa ou televisiva são edições de uma

1. GUIGUE, Arnaud. Cinema e experiência de vida. In: MORIN, Edgar. A religação dos saberes: o desafio do século XXI. Rio de Janeiro: Bertrand Brasil, 2004. realidade muito mais complexa, acredito que o cinema como objeto teórico, estético ou possibilidade de conhecimento histórico possa ser abordado como uma linguagem a qual permite, de maneira original, descobrir, além do que não foi dado a ver pelo cineasta, as inter-relações e as conexões com outros saberes. 
A partir dessas considerações, selecionei dois filmes do diretor Sérgio Rezende: Zuzu Angel (2006) e Lamarca (1994). Os filmes, produzidos em épocas distintas, trazem duas histórias que, embora vividas individualmente, estão interligadas pelos sonhos e pela tragédia: Zuzu Angel, estilista de moda, e Carlos Lamarca, capitão da guerrilha. Entre eles, Stuart Angel, militante do Movimento Revolucionário 8 de Outubro (MR-8), e o Golpe Militar de 1964. Entre eles: o diretor Sérgio Rezende e as polêmicas que seus filmes suscitam em diferentes segmentos sociais e intelectuais. Esse foi um dos motivos da escolha dos filmes, ou seja, a possibilidade de propor um exercício da descoberta do que historicamente não foi dado a ver e da percepção das inter-relações existentes entre informações, memória, documentos, pesquisa histórica, linguagens, pontos de vista, ficções. Apreender, enfim, as conexões entre saberes, uma vez que a poesia será o fio condutor desta minha leitura das cinebiografias propostas².

\section{FICHA TÉCNICA}

Zuzu Angel

Gênero - Drama

Direção - Sérgio Rezende

Roteiro - Marcos Bernstein e

Sérgio Rezende

Produção - Joaquim Vaz de

Carvalho

Produção executiva - Heloísa

Rezende

Música - Cristóvão Bastos

Fotografia - Pedro Farkas

Direção de produção -

Laís Chamma e Mílton Pimenta

Direção de arte - Marcos

Flaksman

Figurino - Kika Lopes

Edição - Marcelo Moraes

Duração - 110 minutos

Lançamento (Brasil) - 2006

Site oficial: <http://www.zuzuan-

gelofilme.com.br $>$

Distribuição - Warner Bros

Brasil, anos 1960. A ditadura militar faz o país mergulhar em um dos momentos mais negros de sua história. Zuzu Angel, uma estilista de moda, ficava cada vez

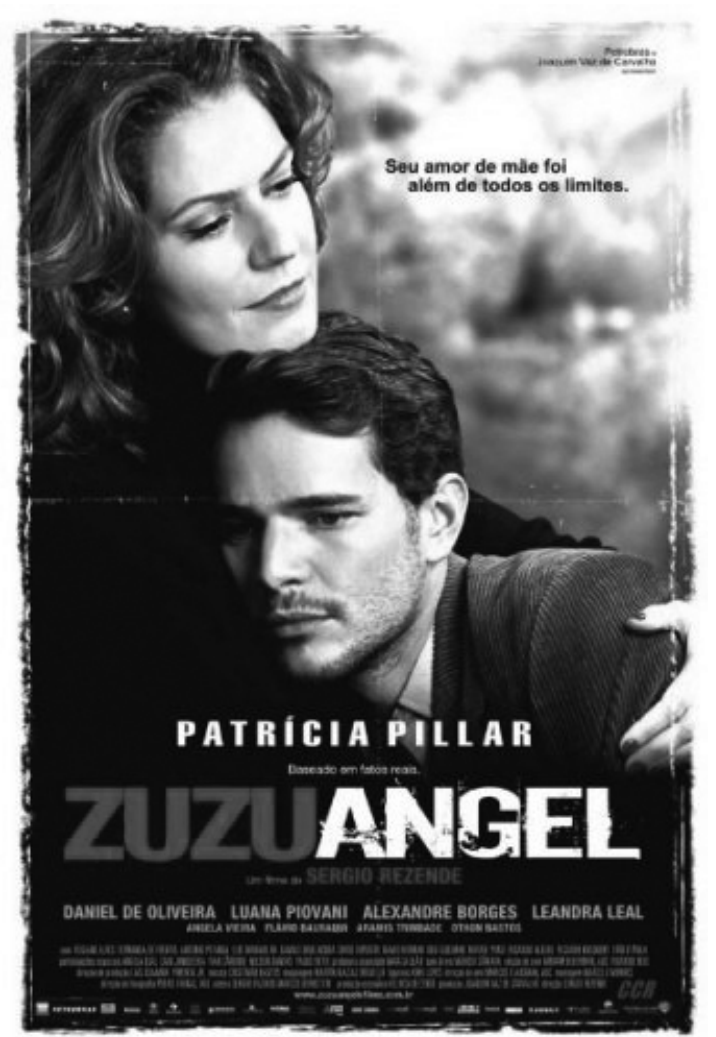

2. <http://www.zuzuangelofilme.com.br>. Acesso em: 14 maio 2007. $<$ http://www.torturanuncamais-rj.org/MDDetalhe. asp?CodMortosDesapare cidos=73>. Acesso em: 14 maio 2007. 
comunicação \& educação • Ano XII • Número 2 • maio/ago 2007

mais famosa no Brasil e no exterior. O desfile da sua coleção em Nova York consolidou sua carreira, que estava em ascensão. Paralelamente, seu filho Stuart Angel Jones ingressava na luta armada. Ela, uma empresária; ele, militante político lutando pela revolução socialista juntamente com Sônia, sua mulher. O desconhecimento das atividades revolucionárias do filho se esclarece na noite em que Zuzu recebe uma ligação, dizendo: "Paulo caiu", ou seja, Stuart tinha sido preso pelos militares. As forças armadas negam sua prisão. Ao receber uma carta dizendo que ele fora torturado até a morte na Base Aérea da Aeronáutica, Zuzu inicia uma batalha aparentemente simples: localizar o corpo do filho e enterrá-lo. A negativa dos militares e a busca incansável pelo corpo do filho mudam sua vida pessoal e política.

\section{FICHA TÉCNICA}

\section{Lamarca}

Roteiro - Sérgio Rezende e Alfredo Oroz, em adaptação livre do livro Lamarca, o capitão da guerrilha, de Emiliano José e Oldack de Miranda Direção de fotografia Antônio Luiz Mendes Câmera e steadycam Marcos Avellar Montagem - Isabelle

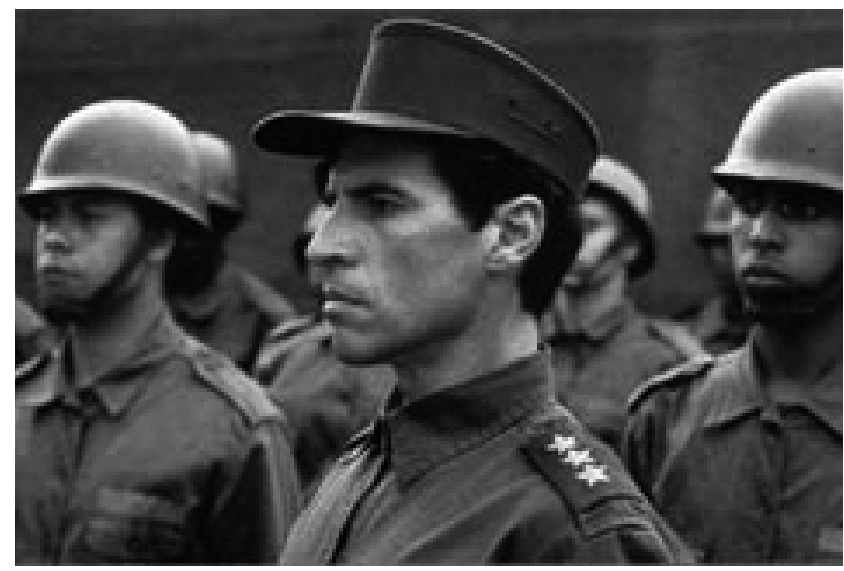

Rathery

Som direto - Jorge Saldanha

Música - David Tygel

Orquestradores - Mauricio Maestro e Vicente Ribeiro.

Participação da Orquestra Filarmônica do Espírito Santo, sob a regência do maestro Helder Trefzger

Direção de arte - Clóvis Bueno

Cenografia - Vera Hamburger

Figurino - Rita Murtinho

Maquiagem de efeitos - Antônio Pacheco

Produção - José Joffily e Mariza Leão

Produção executiva - José Joffily

Direção de produção - Andrea Queiroga

Produção - Cinema Filmes e Morena Filmes

Ano de Produção - 1994

Duração - 120 minutos 
O filme Lamarca conta a história dos dois últimos anos de vida do capitão Carlos Lamarca, que deserta em finais da década de 1960 e ingressa na luta armada contra a ditadura no Brasil. O filme concentra sua narrativa no personagem Lamarca: sua trajetória como oficial do Exército brasileiro, o contato com idéias socialistas, a permanência, em 1962, na Faixa de Gaza, no Egito, perto do Canal de Suez, como integrante da força de paz. Durante o ano em que passa na região, o contato com a miséria dos beduínos no deserto leva-o a questionar se realmente estava lutando do lado certo. O filme também revela o clima de terror instituído pela ditadura e a situação das organizações armadas, diante da estrutura bem montada do Estado.

\section{POESIA E HISTÓRIAS TECIDAS PELA NARRATIVA CINEMATOGRÁFICA}

Se o historiador não é livre nem pode inventar seus personagens, dar-lhes falas e pensamentos, a ficção pode. Como pode também traduzir as imagens que permeiam ou sugerem a literatura e a história através de outras linguagens. No caso, o filme. O que não é possível, no entanto, é perder a noção de que historiadores, cineastas, escritores não reproduzem a realidade, mas representam-nas sob pontos de vista. São construtores de olhares enredados numa história e época.

Sem entrar propriamente no debate existente em torno da necessidade de o historiador buscar novas formas de registrar e narrar os acontecimentos históricos sem que haja uma separação entre narrativas e estruturas, vou seguir um dos caminhos apontados por Peter Burke ${ }^{3}$ e tentar acompanhar como os personagens - Lamarca e Zuzu Angel - foram ficcionados pelo cineasta Sérgio Rezende. Tentar entender até mesmo como os filmes aparecem como uma possibilidade de narrativas históricas na medida em trabalham o centro e as inter-relações. Personagens e acontecimentos históricos justapostos em uma linguagem específica que é a do cinema.

Sérgio Rezende toma como base a biografia Lamarca: o capitão da guerrilha, escrita por Emiliano José e Oldack de Miranda, em 1980. Para compor Zuzu Angel, parte de documentos, correspondências, trabalhos, coleções de moda, livros, nomes, deixados pela estilista, entre outras fontes fornecidas pela filha, a jornalista Hildegard Angel, que também colaborou com conversas e ajustes no filme. Portanto, partindo de documentos, o diretor faz das duas histórias reais uma adaptação para o cinema. Utiliza-se de uma montagem na linguagem cinematográfica, que é, segundo Peter Burke ${ }^{4}$, uma linguagem literária, e produz por meio de imagens e textos um movimento, uma ficção e uma narrativa.
3. BURKE, Peter (Org.). A história dos acontecimentos e o renascimento das narrativas. A escrita da história: novas perspectivas. São Paulo: Editora da Universidade Estadual Paulista, 1992.

4. Ibid. 
comunicação \& educação • Ano XII • Número 2 • maio/ago 2007

No entanto, Sérgio Rezende abre o filme Lamarca com um texto literário e fecha o filme Zuzu Angel com uma música. Poesias, que, datadas em suas produções, são universais em suas escrituras. Como o filme é produto, "uma imagem-objeto, cujas significações não são somente cinematográficas" , e o espectador é também um leitor-produtor de sentidos, vou partir do texto-abertura de Charles Dickens e da música composta por Chico Buarque para Zuzu Angel e propor a realização de um exercício, que tem no texto poético o seu fio condutor, mas que objetiva a pesquisa histórica.

\section{Era o melhor de todos os tempos...}

Era um tempo em que se acreditava na transformação da história, das vidas, da cultura e dos povos por meio de uma revolução. Era um tempo de revoluções e das causas coletivas, de práxis política entendida em suas múltiplas dimensões. Tempo de ideais e de líderes. Nos filmes: o líder Carlos Lamarca e Stuart Angel, um idealista militante da guerrilha urbana.

O diretor, ao passar os slides sobre a trajetória individual e particular da vida de Carlos Lamarca até o momento em que se transforma em líder revolucionário, aponta-nos o recorte histórico com o qual trabalhou, bem como o período da vida de Lamarca: o filme trata dos dois últimos anos de sua vida (1969-1971) e de uma época de acirramento entre forças políticas, quando, na decretação do AI5, muitos, percebendo o fechamento político e a implantação de uma ditadura, saem da resistência pacífica, organizam-se em grupos clandestinos e passam à luta armada.

Lamarca pertencia inicialmente à Vanguarda Popular Revolucionária (VPR), originária da dissidência da Polop (Política Operária). Entrou em discordância com a VPR e, em abril de 1971, passou a integrar o Movimento Revolucionário 8 de Outubro (MR-8), que entendia que a revolução só poderia ser uma revolução socialista.

Ao contar a história de Zuzu Angel, Sérgio também traça o recorte histórico: 1971, data da morte de seu filho, a 1976, data de sua morte.

Ao contar a história pessoal de Lamarca, remete-nos a outros contextos da luta revolucionária, como, por exemplo, a organização dos chamados aparelhos e sua hierarquia interna, algumas das táticas de guerrilha urbana - seqüestros e roubos a banco para financiar a revolução -, bem como nos mostra a incompreensão do povo diante do sentido e do significado da revolução. Em uma das falas, Lamarca diz: "Se o povo tivesse consciência de sua miséria, pegaria

5. FERRO, Marc. O filme: uma contra-análise da sociedade? In: LE GOFF, Jacques; NORA, Pierre. História: novas abordagens. Rio de Janeiro: Francisco Alves, 1976. em armas como nós".

A luta armada, naquele momento, era a luta de uma vanguarda revolucionária que tinha como uma de suas tarefas trabalhar a consciência política das massas. Tarefa ilustrada pelo cineasta em muitas passagens do filme, como o roubo ao banco e a frase: "Viva a revolução", escrita no balcão do banco; ou 
ainda quando Zequinha fala em justiciamento, e Lamarca interfere, explicando a necessidade de fazer um trabalho político, mesmo com aqueles que não se adaptaram à luta.

Stuart Angel, filho de Zuzu Angel, também pertencia ao MR-8, juntamente com sua mulher Sônia. Discutiam os destinos do povo e a necessidade de uma revolução como forma de se libertar dos imperialismos impostos ao terceiro mundo, em especial, do norte-americano. Ligações que tomamos conhecimento nas cenas do assalto ao banco, trazidas nos dois filmes, uma vez que essa era uma das funções de Lamarca na organização: a de comandar seqüestros e expropriações; e durante as seqüências de torturas, quando os torturadores exigem que Stuart diga onde se encontra o capitão Lamarca.

\section{Mas era o pior dos tempos}

Tempos traduzidos nas cenas de torturas, perseguições e desaparecimentos. Tempos de violência e de um regime que, de um lado, construía um discurso de modernidade, de desenvolvimento econômico; e, de outro, torturava, matava e enlouquecia.

Aliás, muitos fugiram para a loucura e

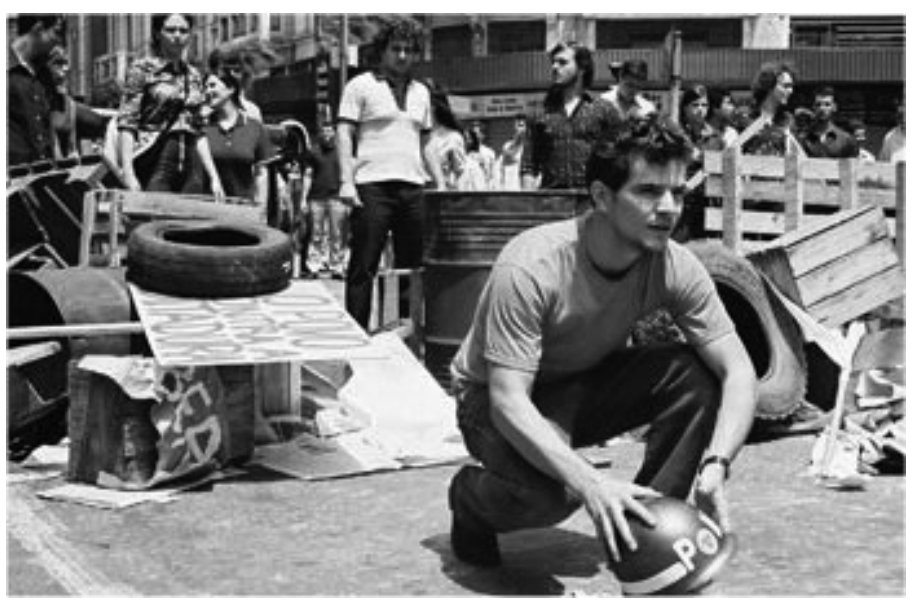
para o suicídio - caso do frei Tito de Alencar Lima, um dos presos políticos libertado em troca do embaixador. Torturado, cometeu suicídio na França.

Dias após receber o telefonema sobre a prisão e o desaparecimento de seu filho, Zuzu recebe uma carta do preso político Alex Polari de Alvarenga, em que narrava as torturas sofridas por Stuart. Alex as havia presenciado: Stuart tinha sido arrastado por um jipe pelo pátio interno da Base Aérea do Galeão, com a boca no cano de descarga do veículo. Também ouviu os gritos dele numa cela ao lado, pedindo água e dizendo que ia morrer; pouco depois, seu corpo foi retirado da cela. Como o de tantos outros, foi jogado no mar.

Era ainda a idade da sabedoria, a idade do disparate; era a época da fé, a época da descrença...

A fé no triunfo de uma revolução que, nas palavras de Lamarca, estava próxima. Acreditava na revolução, e quando o comando do movimento tentou mandá-lo para fora do País, ele reagiu dizendo que não sairia do Brasil nem 
comunicação \& educação • Ano XII • Número 2 • maio/ago 2007

se renderia ou se submeteria à ditadura. Não permitia que a descrença tomasse conta de seus pensamentos e atos. Contra os fracassos políticos da guerrilha urbana, perguntava-se sobre o medo que o poder tinha da guerrilha. A fé, conceito cristão e base do pensamento ocidental, que leva muitas vezes a se pensar o processo histórico como finalista ou salvacionista, tinha ali e para ele o sentido da determinação.

Stuart Angel Jones também não saiu do Brasil quando sua mãe lhe propôs que partisse com Sônia para o exterior. A certeza de que as pessoas faziam escolhas na vida e sua crença na causa revolucionária não permitiram que partisse.

Era a estação da Lua, era a estação da treva, era a primavera da esperança, era o inverno do desespero. Tínhamos tudo a nossa frente. Não tínhamos nada à frente.

Metáforas e contrários em uma mesma história e narrativa, na qual o cineasta introduziu a memória como recurso de linguagem e montagem. Recurso que, longe de empobrecer, comprova que o movimento de imagens e a descontinuidade temporal permitidos pela literatura e pela ficção enriquecem a narrativa e promovem ao historiador e professor um exercício com tempos simultâneos, descontínuos e não-lineares.

No caso de Lamarca, impossibilitado de permanecer no comando da guerrilha urbana, dizimada pela repressão, em que pessoas foram mortas, mutiladas ou desapareceram, ele deixa a cidade e vai para o campo, onde a guerrilha rural estava sendo implantada.

Instalado, porém, sem mobilidade de ação e atuação, Lamarca e Sérgio Rezende investem na memória como base para um novo movimento dentro da história e da narrativa. Agora são dois os narradores dos acontecimentos, em que imagens e falas se justapõem para nos apresentar outros tempos e a interferência daqueles no tempo presente.

Em suas memórias, por exemplo, ficamos sabendo de fatos e acontecimentos que antecederam o período que está sendo contado. Rezende recupera os slides iniciais, o duplo movimento de Lamarca: o pessoal e o político, as lutas internas e as determinações políticas, a guerrilha no Vale do Ribeira.

No exército, suas memórias nos contam a trajetória como tenente, comunista e campeão de tiro. Apesar das suspeitas, a promoção. A fuga em 1969. De seu primeiro casamento, revela-nos a história de Maria Pavan, dos filhos, a dor e o sacrifício da separação. Maria e os filhos foram enviados a Cuba. De si, as memórias da certeza de que seria um desertor do exército, um revolucionário.

Em um dos diálogos com o pai, mostra-nos o desejo de ser soldado, a percepção da realidade quando serviu na zona do Canal de Suez e a descoberta de que a luta militar é uma luta política e a de que não existe liberdade na miséria. O sapateiro, pai de Lamarca, visitado por Zuzu Angel, ouve da estilista, num momento de desespero, que seu filho Stuart havia morrido para deixar o dele, Lamarca, viver. Desculpa-se em seguida, ao perceber uma dor igual, mesmo que por motivos diferentes. 
Se as memórias nos colocam em sintonia com tempos e acontecimentos passados, o tempo presente dos filmes é o tempo das reflexões e dos registros. Uma outra memória. Confluências entre ficção e documento.

Pelos registros podemos acompanhar o sonho/primavera e o inverno de uma outra realidade. De qualquer forma, a determinação e a consciência de que tinham - Lamarca e Stuart - tudo e nada a sua frente. Em 30 de junho de 1971, Lamarca escreve: estejamos onde estivermos, há sempre algo para transformar. Mesmo com a guerrilha urbana fracassada, havia o campo e a continuidade da luta. A esperança agora era o agreste, o sertão. E o trabalho de arregimentar pessoas e fazê-las entender a luta e a necessidade da revolução porque, escrevia: num país de escravos, onde o milagre não havia chegado, o único milagre era fazer a revolução.

A primavera da esperança, descrita em carta datada de 4 de julho de 1971, quando Lamarca saúda os Panteras Negras ${ }^{6}$, vem acompanhada por uma das cenas mais reveladoras. São duas imagens sintetizadas numa única só. São imagens poéticas que as palavras nos permitem vislumbrar: a poesia da esperança, da luta, do desejo de transformar o País e um povo, com uma outra e trágica poesia - o agreste. A voz solitária de um sonho que não encontrava mais nada à sua frente além do sertão, do agreste e do inverno do desespero que estaria por vir.

A voz solitária representada na incansável denúncia das torturas, das mortes e da ocultação de cadáveres praticadas pelo regime em vigência. Conhecida interna e externamente, Zuzu passa a denunciar a morte do filho para a imprensa estrangeira e a deputados norte-americanos, entregando uma carta a Henry Kissinger, que na época era Secretário de Estado.

Voz solitária, porém, incansável, Zuzu Angel fez a primeira coleção de moda política da história. O anjo, que era o símbolo de alegres, tropicais e leves estampas de suas coleções, foi transformado em pássaros engaiolados e balas de canhão disparadas contra anjos. O anjo símbolo do filho desaparecido foi transformado em anjos amordaçados, imagens de meninos aprisionados, sóis atrás de grades.

Pelas memórias vamos tomando conhecimento de sua história e dos acontecimentos que antecederam à morte de Stuart Angel Jones. No tempo presente, na estação das trevas, o medo e a denúncia/anunciação de sua própria morte: "Se eu aparecer morta, por acidente ou outro meio, terá sido obra dos assassinos do meu amado filho".

A partir da seqüência de Lamarca no agreste, Sérgio Rezende constrói duas visões bastante interessantes: de um lado, Lamarca e Zequinha em fuga, perante uma guerra desigual juntando forças - físicas para sobreviver à doença e morais para sobreviver à solidão da luta tão desejada. De outro lado, o caçador e a imagem do melhor tiro.

Num misto de ódio e admiração, a perseguição àquele que ousou não só desafiar o exército, mas, e principalmente, teve a coragem de sonhar e fazer revolução.
6. Partido revolucionário dos EUA, denominado originalmente de Partido Pantera Negra para Autodefesa. Fo fundado em 1966 por Huey Newton e Bobby Seale em Oakland, Califórnia, para proteger residentes negros contra a brutalidade policial. (N.E.) 
comunicação \& educação • Ano XII • Número 2 • maio/ago 2007

Em 17 de setembro de 1971, Lamarca e seu companheiro Zequinha foram mortos no sertão da Bahia.

$\mathrm{O}$ mesmo ódio àquela que se atreveu denunciar as torturas e as práticas utilizadas pelo regime para calar as pessoas que sonharam e lutaram para fazer uma revolução.

Zuzu Angel morreu em 14 de abril de 1976, na Estrada da Gávea, quando saía do túnel Dois Irmãos.

Em suma, era uma época tão semelhante à atual, que algumas das suas mais espalhafatosas autoridades insistem em ser aceitas, para o bem ou para o mal, apenas no grau superlativo. Deuses ou demônios.

\section{DA NARRATIVA CINEMATOGRÁFICA À PESQUISA HISTÓRICA}

Se, na primeira parte do exercício, a poesia conduziu a leitura das histórias narradas pelo cineasta - na tentativa de mostrar que são inúmeras as maneiras de perceber e abordar uma obra -, neste segundo momento é importante recorrer aos teóricos que têm analisado o cinema como fonte documental e propor um outro e necessário exercício, ou seja, a pesquisa como parte da verificação das conexões existentes entre as informações trazidas pelos meios impressos e audiovisuais e os acontecimentos históricos.

Embora em um aspecto historiadores e cineastas estejam mais próximos que aos romancistas, porque é "improvável que sejam capazes de condensar os problemas de uma época na narrativa", é importante termos clareza de alguns critérios de análise do filme como documento capaz de nos levar ao conhecimento de um contexto histórico ou de personagens nesse mesmo contexto. No caso, os personagens Zuzu Angel e Carlos Lamarca, que só serão compreendidos se buscados no contexto histórico, bem como a ficção construída pelo diretor dos filmes, já que este, apesar de apresentar os documentos como fonte e ponto de partida, tem sobre o acontecimento um ponto de vista, e é com base nele que cria sua narrativa cinematográfica.

Não caberá aqui discorrer sobre as diferentes análises feitas, tanto pela crítica como pelos estudiosos da estética cinematográfica a respeito do cinema produzido por Sérgio Rezende, uma vez que os filmes foram escolhidos exatamente pelo que mostram e pelo que deixam de mostrar; e também porque narram a história com base no que os historiadores chamam de história particular, privada - a vida e as lutas de Zuzu Angel e Carlos Lamarca -, em vez de uma história pública, no caso, o período da ditadura militar no Brasil.

Dito isso, penso que podemos levantar alguns pontos que não foram tratados nos filmes de Sérgio Rezende. Sabemos que tanto Lamarca como Stuart Angel Jones pertenciam ao MR-8. Mas a VPR e o MR-8 não eram as únicas organizações armadas existentes. Havia: a Ação Libertadora Nacional (ALN),

7. BURKE, op. cit., p. 340. a Resistência Armada Nacionalista (RAN), a Vanguarda Armada Revolucio- 
nária Palmares (VAR-Palmares), o Partido Operário Comunista (POC), entre outros. Partidos de resistência e luta que nem sempre convergiam em teorias e ações. Especificamente, podemos recuperar a trajetória de Carlos Lamarca desde seus estudos para se tornar um militar até sua experiência no Canal de Suez, quando entra em contato com a miséria dos povos do deserto e passa a ter consciência de que seria um revolucionário; suas influências teóricas, como Che Guevara e Regis Debray, e a teoria do foco guerrilheiro; bem como sua mudança de grupo, da VPR para o MR-8; a relação com Iara Yavelberg; ou ainda a Operação Vale do Ribeira e as bases denominadas Carlos Zanirato e Eremias Delizoikov, mortos pela repressão.

Embora Sérgio Rezende tenha feito das figuras de Lamarca e Zuzu Angel as referências para contar suas histórias, pedem uma pesquisa sobre tantos outros que morreram pela repressão do regime. E, nesse aspecto, o filme Zuzu Angel pode ser exemplar, pois ainda que mostre a luta de uma estilista famosa para denunciar e recuperar o corpo de seu filho, ela pode ser entendida como uma entre tantas mães que tiveram seus filhos mortos pela ditadura e que também nunca puderam enterrá-los, já que seus corpos desapareceram no mar ou em valas comuns. Ou uma pesquisa sobre as inúmeras mulheres torturadas e mutiladas física ou emocionalmente pelo regime, caso de Sônia, mulher de Stuart, também morta pela repressão, e de Iara, companheira de Lamarca que cometeu suicídio. Em uma de suas falas, diz o quanto era estranho viver sabendo que não ia envelhecer. Ou, ainda, uma investigação dos outros movimentos de resistência ao regime militar, como o movimento estudantil e os movimentos artísticos e culturais daqueles anos.

Enfim, são inúmeras as possibilidades e as temáticas sobre esse período pouco conhecido e estudado de nossa história. E a despeito de sua aparência desinteressantemente fora de contexto, existe uma geração de jovens que desconhecem tais acontecimentos e, apesar de uma parte da crítica considerar os filmes de Sérgio Rezende superficiais e pouco críticos em relação à matéria-prima com a qual trabalha, não deixa de ser interessante sua preocupação em trazer para o cinema uma parte de nossa memória histórica.

Em setembro de 1994, a historiadora Mary Eunice Ramalho de Mendonça escreveu:

Lamarca é hoje um dos poucos filmes que retomam a linha dos anos sessenta, num país onde a História, a memória e, portanto, a identidade nacional são pouco priorizadas dentro da política cultural (existe?) do governo. Procurando recuperar a memória nacional, o filme desmistifica a política do duplo discurso do Milagre Brasileiro (1969-1972), que se ocultava sob a euforia do falso nacionalismo - através de slogans como Brasil, ame-o ou deixe-o, as torturas, as mortes e a guerra civil que aconteciam neste país. O diretor Sérgio Rezende realiza o filme com um roteiro bem escrito e segundo a dramaturgia pela qual optou, isto é, quase didática. Talvez a mais adequada para o resgate de memória nesse momento. Muitos críticos, porém, não aprovam a simplificação dramatúrgica, que não corresponde à criatividade do cinema político dos anos sessenta, profundamente dialético na sua linguagem ${ }^{8}$.
8. MENDONÇA, Mary Eunice Ramalho. Lamarca. O filme. Revista Comunicação \& Educação, São Paulo: CCA/ECA/USP/ Moderna, n. 1, p. 73-74, set./dez. 1994 
9. HUIZINGA, apud BURKE, Peter (Org.). A história dos acontecimentos e o renascimento das narrativas. In: A escrita da história: novas perspectivas. São Paulo: Editora da Universidade Estadual Paulista, 1992. p. 327-348.

10. FERRO, Marc. O filme: uma contra-análise da sociedade? In: LE GOFF, Jacques; NORA, Pierre. História: novas abordagens. Rio de janeiro: Francisco Alves, 1976.

11. BURKE, op. cit.

12. LUZ, Rogério. Filme e subjetividade. Rio de Janeiro: Contra-capa Livraria, 2002.

13. MORIN, Edgar. Amor, poesia, sabedoria: ensaios. Rio de Janeiro: Bertrand do Brasil, 2006. p. 36.

Ao historiador cabe a reflexão sobre a citação anterior; é a mesma preocupação de Huizinga, quando nos lembra de que devemos evitar "a personificação porque esta é uma figura de retórica que obscurece a distinção entre líderes e seus seguidores, além de encorajar os leitores sem grande imaginação a suporem o consenso de grupos que estavam em freqüentes conflitos"9.

Como também cabem as reflexões de Marc Ferro ${ }^{10}$ sobre a relação cinema/ história, e a de Peter Burke ${ }^{11}$ de que devemos praticar a heteroglossia, ou seja, aprender a ler em muitas direções, perceber que as vozes da história se deslocaram e que são variadas e opostas. Ao professor, cabe o estudo dos teóricos e da apreensão desse deslocamento de vozes e da percepção do cinema como fonte de estudo, conhecimento e linguagem que torna possível a religação dos saberes; ou, se preferir, pode valer-se do texto de Rogério Luz, no qual diz que o cinema é "a força que desprende da terra - da posição ereta do homo sapiens - e sobrevoa, em velocidade infinita, paisagens de afetos desenhadas no elemento sensível da imagem auditiva e visual"12; e, a partir daí, enveredar para outros estudos do cinema.

Para concluir, podemos recuperar Edgar Morim, quando escreve sobre a poesia e a prosa: "Poesia-Prosa constituem, portanto, o tecido de nossa vida. Hölderin afirmava: 'O homem habita a terra poeticamente'. Acredito ser necessário dizer que o homem a habita, simultaneamente, poética e prosaicamente. Se não houvesse prosa, não haveria poesia"13.

E dizer: Charles Dickens e Chico Buarque de Hollanda... Sempre!

Resumo: A proposta desta videografia, a partir dos filmes Zuzu Angel (2006) e Lamarca (1994), é um fazer exercício de descoberta do que historicamente não foi dado a ver e de percepção das interrelações existentes entre informações, memória, documentos, pesquisa histórica, linguagens, pontos de vista, ficções. Apreender, enfim, as conexões entre saberes, uma vez que a poesia será o fio condutor desta leitura das cinebiografias propostas.

Palavras-chave: cinema, ficção, memória, poesia, história.
Abstract: This videography proposes, starting with the motion pictures Zuzu Angel (2006) and Lamarca (1994), an exercise of discovering what historically was not shown nor realized of the existing interrelationship among information, memory, documents, historical research, languages, points of view, stories. The purpose is to perceive the connections among different types of knowledge, once that poetry is the conducting line in the reading of the listed cinebiographies.

Keywords: cinema, fiction, memory, poetry, history. 